\title{
Phosphorus effects on root growth and development in two maize genotypes
}

\author{
M.A. HAJABBASI and T.E. SCHUMACHER \\ Plant Science Department, South Dakota State University, Brookings, SD 57007, USA
}

Received 13 January 1993. Accepted in revised form 13 July 1993

Key words: growth stage, nodal roots, phenotypic plasticity, relative growth rate, root surface area, seminal roots, Zea mays L.

\begin{abstract}
Soil phosphorus (P) availability is critical for the early growth and development of maize (Zea mays L.). Soil $\mathbf{P}$ also affects root morphological and physiological characteristics that are important for $\mathrm{P}$ uptake. The objective of this study was to evaluate the effects of $P$ on seedling root growth and development of two maize genotypes differing in root system plasticity. Two maize genotypes, CM37 (high plasticity) and W153R (low plasticity), were selected based on a preliminary study. Maize plants were evaluated at six vegetative stages of development for three soil $P$ treatments $\left(0,45\right.$, and $\left.300 \mathrm{mg} \mathrm{kg}^{-1}\right)$. Seedlings were grown in a controlled environment using a soil with low native P, Maddock sandy loam (sandy, mixed Udorthentic Haploborolls). The addition of $\mathrm{P}$ decreased the time to reach a given growth stage and increased the relative growth rate of roots to a greater degree in CM37 than in W153R. The effects of $\mathrm{P}$ on shoot dry weight and root surface area during the V4-V6 growth period appeared to be related to the effects of $\mathrm{P}$ on development and relative growth rates during the V1-V3 growth period. Evaluation of the time course of phenotypic change is an important consideration when developing adapted genotypes for specific environments.
\end{abstract}

\section{Introduction}

Soil phosphorus (P) availability during maize seedling development is an important determinant of growth and grain yield. Barry and Miller (1989) reported a significant increase in maize yield in response to $\mathbf{P}$ fertilization before the 6-leaf stage (V6) compared to the addition of $P$ after the V6 stage. The authors attributed the yield increase to more kernels per ear. Axillary meristems that develop into the future ear are formed by the V6-V7 growth stage.

Root growth and development are critical for early $P$ uptake in maize since $P$ is relatively unavailable and immobile in many soils (Barber, 1984). P uptake is dependent on root length, diameter, and surface area in contact with the soil (Anghinoni and Barber, 1980). The concentration of soluble $P$ in the soil also determines root morphology such as root diameter, root length, lateral root formation, and root surface area (Schenk and Barber, 1979; Zhang and Barber, 1992). The ability of a genotype to increase root surface area in response to soil $\mathrm{P}$ levels could help support high rates of $P$ uptake during early stages of growth. There is significant genetic variation in $\mathrm{P}$ uptake, accumulation and use in maize (Clark, 1983). However, selection criteria are not always easily defined due to the complexity of factors controlling $\mathbf{P}$ in the plantsoil system and because of the difficulty in defining optimal phenotypes for specific environments (Fox, 1978; Robinson, 1989).

The purpose of this study was to evaluate the 
effects of different initial concentrations of soil $\mathrm{P}$ on root growth and development of two maize genotypes selected for differences in root system plasticity.

\section{Materials and methods}

Two maize genotypes, CM37 and W153R, were studied for the first six growth stages, (V1-V6) (Hanway, 1966). The two maize genotypes were selected from a preliminary study examining root morphological responses to temperature (Schumacher, 1984). In this study, CM37 was found to have a greater density of lateral roots as root zone temperature increased $\left(12 \mathrm{~cm}^{-1}\right.$ at $15^{\circ} \mathrm{C}$ and $19 \mathrm{~cm}^{-1}$ at $25^{\circ} \mathrm{C}$ ) compared to W153R $\left(5 \mathrm{~cm}^{-1}\right.$ at $15^{\circ} \mathrm{C}$ and $6 \mathrm{~cm}^{-1}$ at $25^{\circ} \mathrm{C}, \mathrm{LSD}_{0.05}$ for both comparisons, $2 \mathrm{~cm}^{-1}$ ). As a result of the greater variability in lateral root density across temperatures CM37 was considered more plastic than W153R.

Maize seeds were germinated in a germinator/ incubator at a temperature of $22^{\circ} \mathrm{C}$ for 72 hours. The germinated seeds were planted into pots containing $0.50 \mathrm{~kg}$ soil at a bulk density of $1.1 \mathrm{Mg} \mathrm{m}^{-3}$. Maddock sandy loam (sandy, mixed Udorthentic Haploborolls) was used in this study because of its low native $\mathrm{P}$ content. $\mathrm{P}$ in the form of $\mathrm{NH}_{4} \mathrm{H}_{2} \mathrm{PO}_{4}$, was added to the soil to bring the soil to predetermined soil test levels representing low ( $5 \mathrm{mg} \mathrm{kg}^{-1}$ ), high ( $45 \mathrm{mg} \mathrm{kg}^{-1}$ ), and very high (300 $\mathrm{mg} \mathrm{kg}^{-1}$ ) P test levels. Soil test levels were used to determine the addition of other nutrients. Phosphorous was colorimetrically determined from Bray 1 extracts; nitrogen test levels were determined from water extracts using a nitrate ion selective electrode; an ammonium acetate extract and atomic absorption procedures were used to determine potassium test levels; and zinc was determined using DTPA extraction and atomic absorbtion (Dahnke, 1988; Page et al. 1982). Soil treatments were prepared two weeks prior to planting (Table 1).

Temperature in the growth chamber was controlled between $26^{\circ} \mathrm{C}$ during light periods and $18^{\circ} \mathrm{C}$ during dark periods. Relative humidity varied between $75-95 \%$. A light/dark cycle of $16 / 8 \mathrm{~h}$ was maintained for the duration of the
Table 1. Soil nutrient test levels $\left(\mathrm{mg} \mathrm{kg}^{-1}\right)$ before and after addition of nutrients to Maddox sandy loam

\begin{tabular}{lcrcc}
\hline Nutrient & Before & \multicolumn{2}{c}{ After } \\
\cline { 3 - 5 } & & Low & High & Very high \\
\hline Phosphorus & 2 & 5 & 45 & 300 \\
Nitrogen & 36 & 60 & 64 & 68 \\
Potassium & 40 & 285 & 280 & 300 \\
Zinc & 0.4 & 6 & 10 & 15 \\
\hline
\end{tabular}

experiment. Photon flux density (400-700 nm) measured at canopy height was maintained at an average of $710 \mu \mathrm{mol} \mathrm{m} \mathrm{m}^{-2} \mathrm{~s}^{-1}$ with a maximum of $970 \mu \mathrm{mol} \mathrm{m} \mathrm{m}^{-2} \mathrm{~s}^{-1}$ for two hours in the middle of the light cycle. The pots were watered daily to pot capacity $\left(0.16 \mathrm{~m}^{3} \mathrm{~m}^{-3}\right)$ by weighing. Pot capacity was determined by allowing representative saturated pots to drain for 48 hours and determining water content. Plants were harvested at the beginning of each growth stage for the V1-V6 stages. Stages of growth were identified by counting the number of leaves fully emerged from the whorl when the leaf collar first became visible (Hanway, 1966). A perchloric acid digestion and a vanadomolybdophosphoric acid colorimetric method was used to measure the P content of the shoots (Gelderman, 1990).

Roots were removed by soaking the pots in a container filled with water and gently washing the soil from the roots. The water in the container was screened through a $0.5 \mathrm{~mm}$ sieve to avoid the loss of small roots. Roots were blotted dry and weighed to determine root fresh weight. Root length was measured using a modified line intersect method (Newman, 1966). The mean root radius ( $R$ ) was calculated from $\mathbf{R}=$ $\sqrt{(\mathrm{RFW} /(\mathrm{L} \times \pi))}$, where $V$ is square root, RFW is root fresh weight, $\mathrm{L}$ is root length and $\pi=$ 3.14 (Schenk and Barber, 1979). Root surface area (RSA) was determined by multiplying the root length by the mean root diameter and $\pi$. The lateral roots of the first $10 \mathrm{~cm}$ of the main seminal root of each plant were counted to obtain the density of seminal lateral roots. The number of nodal and seminal roots were counted for each plant.

The study was designed as a randomized complete block design with two blocks consisting of the growth chamber runs. There were four replications within each block, and these were 
analyzed as subsamples. The treatment factors consisted of two genotypes $(G)$, three $P$ treatments (P), and six leaf stages (S). Blocks were considered random while the other factors were considered fixed ( $G, P$, and S). Analysis of variance procedures were used to analyze the data using the MGLH (Multivariate General Linear Hypothesis) procedure of SYSTAT (Wilkinson, 1990).

Relative growth rates for root surface area $\left(\mathrm{RGR}_{\mathrm{sa}}\right)$ were evaluated between growth stages with the following equation as modified for root surface area (Hunt, 1982):

$$
\mathrm{RGR}_{\mathrm{sa}}=\left(\ln \mathrm{RSA}_{\mathrm{n}+1}-\ln \mathrm{RSA}_{\mathrm{n}}\right) /\left(\mathrm{t}_{\mathrm{n}+1}-\mathrm{t}_{\mathrm{n}}\right)
$$

where $\mathrm{RSA}=$ root surface area $\left(\mathrm{cm}^{2}\right) ; \mathrm{t}=$ time (days) $\mathbf{n}=$ growth stage.

Likewise, the mean instantaneous $\mathrm{P}$ uptake rate (lp) $\left(\mu \mathrm{mol} \mathrm{cm} \mathrm{cm}^{-2} \mathrm{day}^{-1}\right)$ was modified for root surface area from equations given by Loneragan and Asher, 1967.

$$
\begin{aligned}
l p= & {\left[( \operatorname { l n } \operatorname { R S A } _ { n + 1 } - \operatorname { l n } \operatorname { R S A } _ { n } ) \left(P_{n+1}\right.\right.} \\
& \left.\left.-P_{n}\right)\right] /\left[\left(t_{n+1}-t_{n}\right)\left(\operatorname{RSA}_{n+1}-\operatorname{RSA}_{n}\right)\right]
\end{aligned}
$$

where $\mathrm{RSA}=$ the root surface area $\left(\mathrm{cm}_{2}\right) ; \mathrm{t}=$ time (days); $\mathrm{P}=$ Phosphorus content $(\mu \mathrm{mol}$ plant $\left.^{-1}\right) ; \mathrm{n}=$ growth stage.

\section{Results}

The time to reach a given growth stage was reduced by $P$ treatments in both genotypes (Fig. 1). The effects of $P$ on development were greater in CM37. The very high $P$ treatment of CM37 reached the V6 stage 3 days earlier than W153R compared to 1 day earlier in the control treatment. The effects of $\mathrm{P}$ on plant development were observed as early as the V2 stage of development.

Shoot dry weight and root surface area were increased by $\mathrm{P}$ treatment in both genotypes even though the time to reach a specific growth stage was much reduced by $P$ treatment (Figs. 1 and 2 ). The developmental isolines in figures 1 and 2 show that after the V3 stage the effects of $P$ on shoot dry weight and root surface area at a given growth stage were less than at a given plant age.

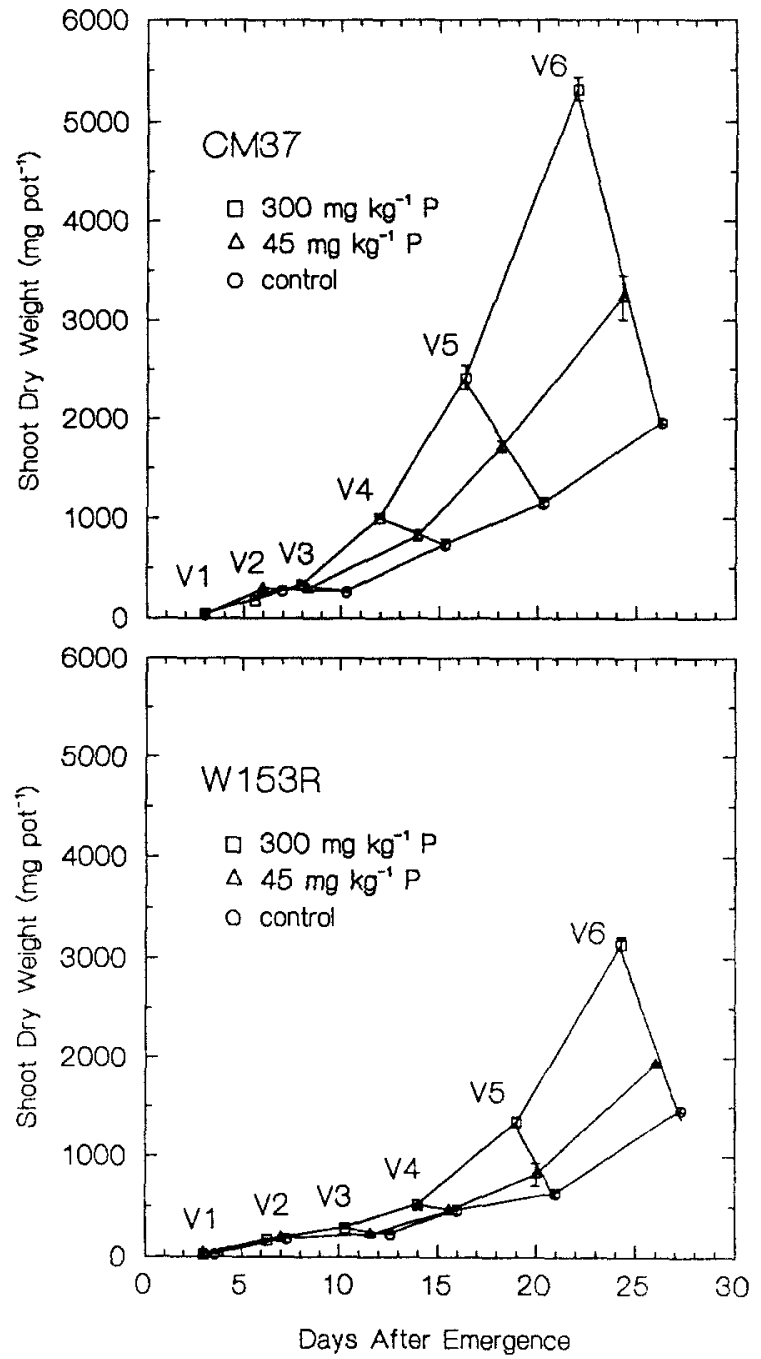

Fig. 1. The effects of $\mathrm{P}$ treatments on shoot dry weight for the V1-V6 growth stages of the CM37 and W153R genotypes. The regression lines between $\mathbf{P}$ treatments for a given growth stage represent developmental isolines. The error bars represent standard errors calculated for each mean $(\mathrm{n}=8) . \quad \mathrm{LSD}_{0.05}$ for the $\mathrm{G} \times \mathrm{P} \times \mathrm{S}$ interaction $=155 \mathrm{mg}$ pot $^{-1}$.

The effects of $\mathrm{P}$ on shoot dry weight and root surface area were greater in CM37 compared to W153R after the V3 stage (Table 2, Figs. 1 and 2). Shoot dry weight at the V6 stage was $69 \%$, $65 \%$ and $33 \%$ higher in CM37 than W153R at the $300 \mathrm{mg} \mathrm{kg}^{-1}, 45 \mathrm{mg} \mathrm{kg}^{-1}$ and control $\mathrm{P}$ rates, respectively. This compared to a difference at the V6 stage in root surface area between CM37 and W153R of $176 \%, 150 \%$, and $85 \%$ at the $300 \mathrm{mg} \mathrm{kg}^{-1}, 45 \mathrm{mg} \mathrm{kg}^{-1}$, and control $P$ rates, respectively. The difference in growth curves can 

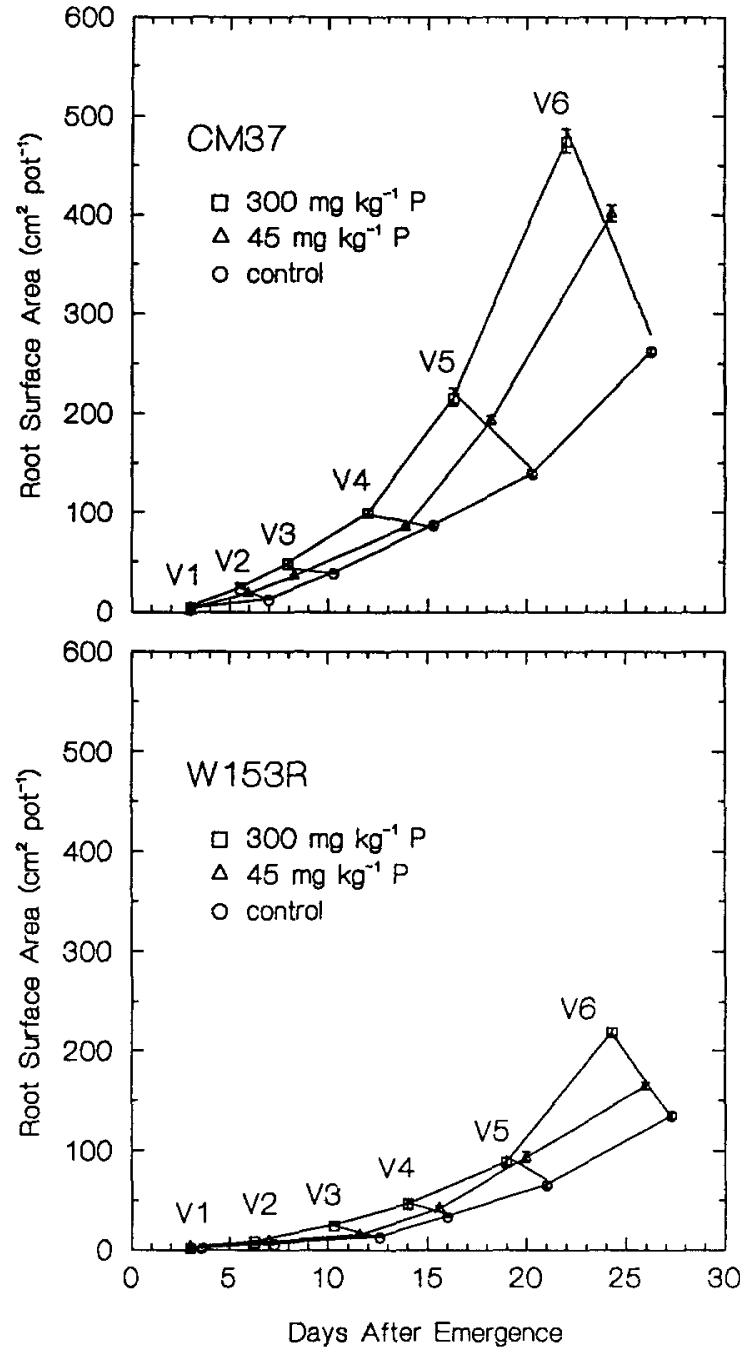

Fig. 2. The effects of $P$ treatments on root surface area for the V1-V6 growth stages of the CM37 and W153R genotypes. The regression lines between $P$ treatments for a given growth stage represent developmental isolines. The error bars represent standard errors calculated for each mean $(\mathrm{n}=8) . \mathrm{LSD}_{0.05}$ for the $\mathrm{G} \times \mathrm{P} \times \mathrm{S}$ interaction $=9 \mathrm{~cm}^{2}$ pot $^{-1}$. be attributed to differences in both development and relative growth rates resulting from genotype interactions with $\mathrm{P}$ treatment and growth stage (Table 2).

The mean relative growth rates for root surface area $\left(\mathrm{RGR}_{\mathrm{sa}}\right)$ depended on genotype, stage, and $P$ treatment (Table 2). Between V1 and V2 the $R_{G R}$ was increased by $P$ relatively more in CM37 than in W153R (Fig. 3). The RGR sa $_{\text {curve }}$ was nearly identical for the 45 and $300 \mathrm{mg} \mathrm{kg}^{-1}$ treatments of CM37. Only the highest $P$ treatment had an effect on $\mathrm{RGR}_{\mathrm{sa}}$ in W153R. The control and the $45 \mathrm{mg} \mathrm{kg}^{-1}$ curves for W153R are nearly identical.

The effects of $\mathrm{P}$ on mean root diameter were observed early in seedling development (Fig. 4). The addition of $P$ at both rates resulted in smaller mean root diameters in CM37 compared to the control for growth stages V1-V4. Only the $P$ rate of $300 \mathrm{mg} \mathrm{kg}^{-1}$ at the $\mathrm{V} 1$ stage resulted in a smaller mean root diameter for W153R.

The appearance of nodal roots was similar in both genotypes (Table 3 ). The highest $\mathrm{P}$ rate advanced the appearance of nodal roots at the V5 growth stage in both genotypes. The number of seminal roots ( 5 at V6) was not affected by genotype or $\mathrm{P}$ treatment (Table 2).

There was a difference between genotypes in terms of lateral root density (the number of lateral roots per length of seminal root) measured at V6 $\left(20 \mathrm{~cm}^{-1}\right.$ of seminal root for CM37 compared to $12 \mathrm{~cm}^{-1}$ for W153R, $\mathrm{LSD}_{0.05}=$ $3 \mathrm{~cm}^{-1}$ ). $\mathrm{P}$ treatments and the genotype $\times \mathbf{P}$ interaction were not significant. This is similar to the findings of Drew (1975) where differences in barley lateral root density along the seminal root were primarily observed only when there was a

Table 2. Probabilities of the $\mathrm{F}$ test for the analysis of variance for shoot and root variables

\begin{tabular}{|c|c|c|c|c|c|c|c|}
\hline \multirow[t]{2}{*}{ Source } & \multicolumn{7}{|c|}{ Shoot and root variables ${ }^{a}$} \\
\hline & SDW & RSA & RD & $\mathrm{SN}$ & NN & $\mathrm{RGR}_{\mathrm{sa}}$ & IP \\
\hline G (genotype) & 0.01 & 0.01 & $<0.01$ & 0.69 & 0.69 & $<0.01$ & $<0.01$ \\
\hline $\mathrm{P}$ (phosphorous) & $<0.01$ & $<0.01$ & 0.02 & 0.06 & 0.18 & 0.01 & 0.03 \\
\hline $\mathbf{S}$ (stage) & $<0.01$ & $<0.01$ & $<0.01$ & 0.01 & $<0.01$ & $<0.01$ & $<0.01$ \\
\hline$G \times P$ & $<0.01$ & $<0.01$ & 0.14 & 0.36 & 0.96 & 0.01 & 0.02 \\
\hline $\mathrm{G} \times \mathrm{S}$ & $<0.01$ & $<0.01$ & $<0.01$ & 0.61 & 0.59 & $<0.01$ & $<0.01$ \\
\hline $\mathbf{S} \times \mathbf{P}$ & $<0.01$ & $<0.01$ & $<0.01$ & 0.40 & $<0.01$ & $<0.01$ & $<0.01$ \\
\hline $\mathbf{G} \times \mathbf{S} \times \mathbf{P}$ & $<0.01$ & $<0.01$ & $<0.01$ & 0.25 & 0.77 & $<0.01$ & 0.01 \\
\hline
\end{tabular}

${ }^{a}$ SDW $=$ shoot dry weight; RSA = root surface area; RD = root diameter; $\mathrm{SN}=$ seminal root number; $\mathrm{NN}=$ nodal root number; $\mathrm{RGR}_{\mathrm{sa}}=$ relative root growth rate; $\mathrm{IP}=$ instantaneous $\mathrm{P}$ uptake rate. 

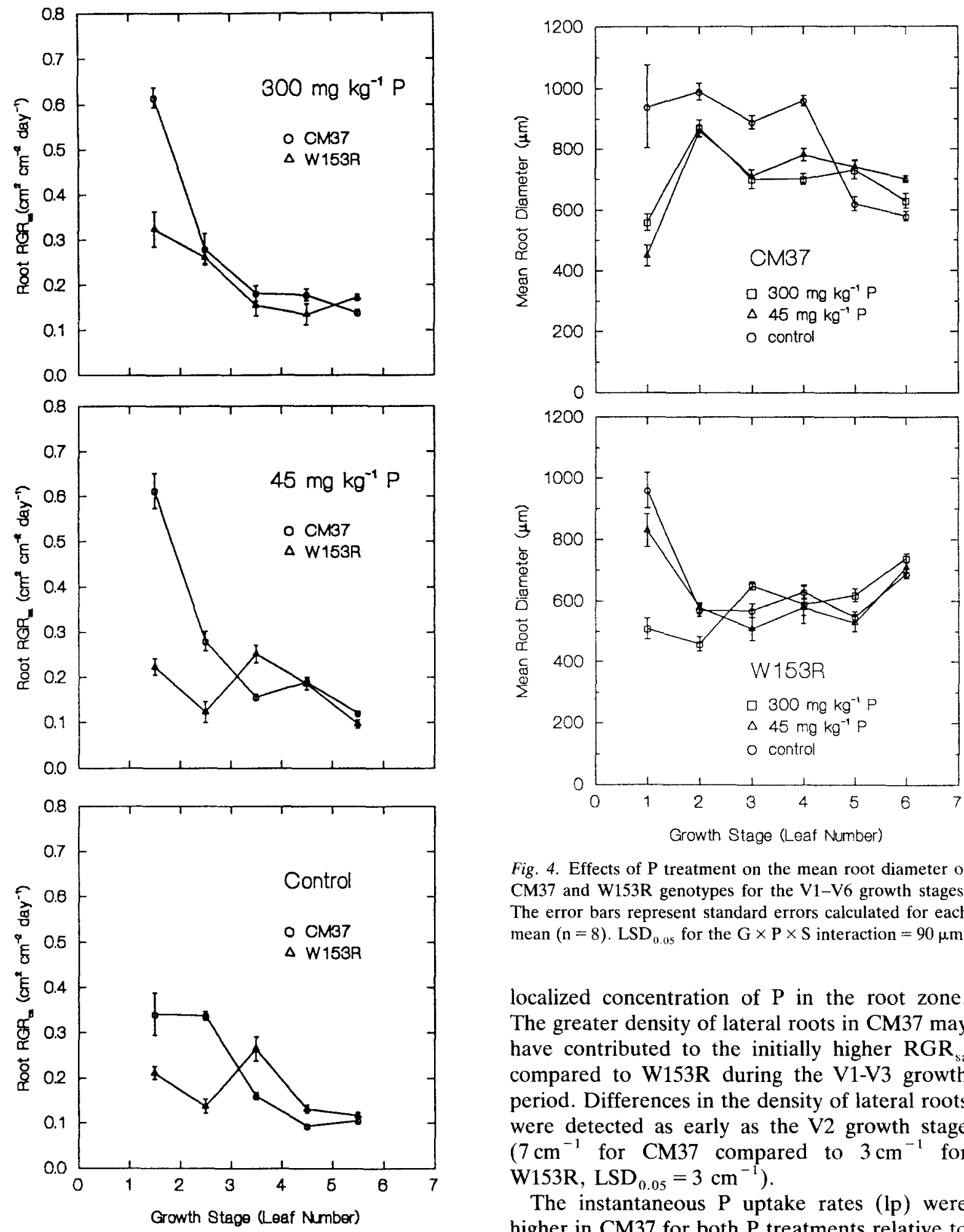

Fig. 3. Relative growth rates of root surface area $\left(\mathrm{RGR}_{\mathrm{sa}}\right)$ for the V1-V6 growth stages of the CM37 and W153R genotypes and $P$ treatments. The error bars represent standard errors calculated for each mean $(n=8) . \mathrm{LSD}_{0.05}$ for the $\mathrm{G} \times \mathrm{P} \times \mathrm{S}$ interaction $=0.07 \mathrm{~cm}^{2} \mathrm{~cm}^{-2} \mathrm{day}^{-1}$.

Fig. 4. Effects of $\mathrm{P}$ treatment on the mean root diameter of CM37 and W153R genotypes for the V1-V6 growth stages. The error bars represent standard errors calculated for each mean $(n=8) . L_{0.05}$ for the $G \times P \times S$ interaction $=90 \mu \mathrm{m}$.

localized concentration of $\mathrm{P}$ in the root zone. The greater density of lateral roots in CM37 may have contributed to the initially higher $R_{G R}$ compared to W153R during the V1-V3 growth period. Differences in the density of lateral roots were detected as early as the $\mathrm{V} 2$ growth stage $\left(7 \mathrm{~cm}^{-1}\right.$ for CM37 compared to $3 \mathrm{~cm}^{-1}$ for W153R, $\operatorname{LSD}_{0.05}=3 \mathrm{~cm}^{-1}$ ).

The instantaneous $\mathrm{P}$ uptake rates (lp) were higher in CM37 for both $\mathrm{P}$ treatments relative to the control during the V1-V3 growth period (Fig. 5). The lp of the very high $P$ treatment in W153R was greater than the control only during the V1-V2 growth period in W153R. CM37 
Table 3. Nodal root appearance by growth stage as affected by $\mathrm{P}$ treatment for the CM37 and W153R genotypes

\begin{tabular}{|c|c|c|c|c|c|c|c|}
\hline \multirow[t]{3}{*}{ Genotype } & \multirow{3}{*}{$\begin{array}{l}\mathbf{P} \\
\left(\mathrm{mg} \mathrm{kg}^{-1}\right)\end{array}$} & \multicolumn{6}{|c|}{ Growth stage } \\
\hline & & V1 & $\mathrm{V} 2$ & V3 & V4 & V5 & V6 \\
\hline & & \multicolumn{6}{|c|}{ Nodal root number } \\
\hline \multirow[t]{3}{*}{ CM37 } & 0 & 0 & 0 & 2 & 4 & 8 & 12 \\
\hline & 45 & 0 & 0 & 2 & 4 & 8 & 12 \\
\hline & 300 & 0 & 0 & 2 & 4 & 11 & 13 \\
\hline \multirow[t]{3}{*}{ W153R } & 0 & 0 & 0 & 3 & 4 & 8 & 12 \\
\hline & 45 & 0 & 0 & 3 & 3 & 9 & 12 \\
\hline & 300 & 0 & 0 & 2 & 4 & 12 & 12 \\
\hline
\end{tabular}

$\mathrm{LSD}_{0.05}=2^{\mathrm{a}}$

${ }^{a} \mathrm{LSD}_{0.05}$ value applies only to comparisons for the $P$ treatment $\times$ stage interaction.

responded to the $\mathrm{P}$ treatments with a significantly higher lp than W153R during the V1-V3 growth period. lp values declined with plant age as observed by others (Nielsen and Barber, 1978).

\section{Discussion}

The genotype selected for greater plasticity in the root system, CM37, appeared to respond sooner and to a greater degree to $\mathrm{P}$ than did W153R. Differences in shoot dry weight and root surface area between the genotypes and $\mathrm{P}$ treatments were most apparent after the V3 stage. However, this appeared to be primarily based on differences in development and relative growth rates that occurred before this stage of development. The effects of $\mathrm{P}$ on development rates and relative growth rates were observed principally between the V1-V3 stages of growth. The greater shoot size and root surface area due to $\mathrm{P}$ treatment in CM37 compared to W153R appeared to be related to factors occuring during the earliest stages of growth including enhanced relative $\mathbf{P}$ uptake rates (lp) and greater sensitivity to soil $\mathbf{P}$ in terms of effects on development and relative growth rates. Other factors not measured in our study, such as root hair production and length, and root induced changes in
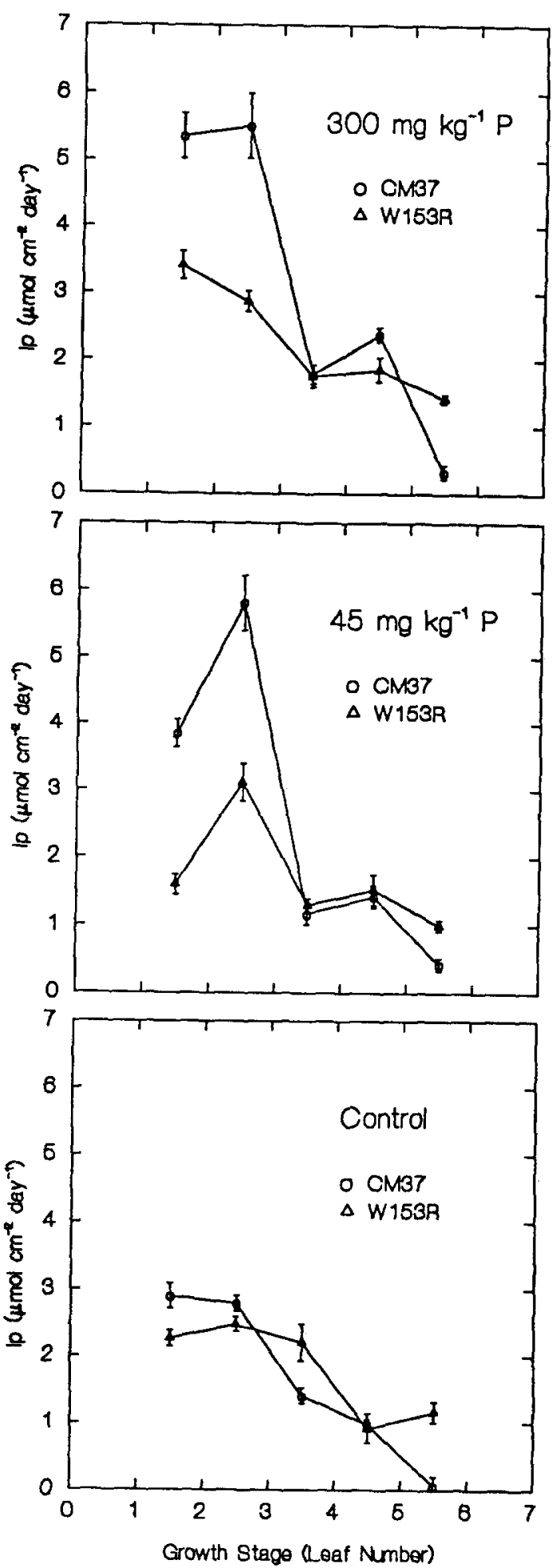

Fig. 5. Mean instantaneous $P$ uptake rates (lp) for the CM37 and W153R genotypes and $P$ treatments for the V1-V6 growth stages. The error bars represent standard errors calculated for each mean $(n=8) . \mathrm{LSD}_{0.05}$ for the $\mathrm{G} \times \mathrm{P} \times \mathrm{S}$ interaction $=0.63 \mu \mathrm{mol} \mathrm{cm}{ }^{-2}$ day $^{-1}$. 
$P$ solubility in the rhizosphere could also be important in describing the genotypic differences in $P$ response (Föhse et al., 1991).

W153R has been identified as a genotype that is tolerant of low P (Da Silva and Gabelman, 1992; Nielsen and Barber, 1978). However, in a study examining six $\mathrm{P}$ concentrations in a sandalumina culture medium, the shoot dry weight of W153R was less responsive to the addition of $P$ compared to other inbred lines (Da Silva and Gabelman, 1992). This is similar to the findings of our study where W153R responded to $\mathrm{P}$ to a lesser extent than CM37 and primarily at the very high $P$ rate. The reduced sensitivity to $P$ in the soil environment found in W153R is characteristic of plants that grow in stress environments (Grime, 1975). However, under the heterogenous and highly competitive situations associated with most agronomic environments, a lack of environmental sensitivity (plasticity) may be a disadvantage.

Our study suggests that the timing of phenotypic change in response to the environment is also an important criteria to evaluate in addition to the final phenotype. Robinson (1989) proposed that there are sets of phenotypes optimal for a given environment rather than a single optimal phenotype. The identification of optimal sets of phenotypes requires the evaluation of genotypes for multiple traits in the range of environments found at a given location (O'Toole and Bland, 1987). The time course of phenotypic change must also be considered.

The selection of genotypes with improved seedling uptake of $\mathrm{P}$ may be more appropriate for high yield environments than for low yield environments where $\mathrm{P}$ efficiency is critical. Increased $\mathrm{P}$ uptake during early growth stages when growing season and soil conditions are ideal (high yield environment) could affect yield through improved kernel meristem development prior to the V7 stage (Barry and Miller, 1989). Fox, (1978), found that short term greenhouse studies using seedlings to evaluate $P$ efficiency in low $\mathrm{P}$ environments did not correlate with field evaluations. Improved seedling uptake of $P$ is likely to be less critical in low yield environments and other traits may be more important in defining optimal phenotypes in these environments.

\section{Acknowledgements}

The authors are grateful to Dr W E Riedell for helpful suggestions in the preparation of the manuscript and to Dr Z Wicks III for providing the maize seeds. Published as South Dakota Experiment Station Article No. 2705. This work is a part of $\mathrm{M} \mathrm{A}$ Hajabbasi's dissertation in partial fulfillment of the requirements for the Ph.D. degree. Present address for M A Hajabbasi is Isfahan University of Technology, Isfahan, Iran.

\section{References}

Anghinoni I and Barber S A 1980 Phosphorus influx and growth characteristics of corn roots as influenced by $P$ supply. Agron. J. 72, 685-688.

Barber S A 1984 Soil Nutrient Bioavailability: A Mechanistic Approach. John Wiley and Sons, Inc., New York.

Barry D A J and Miller M H 1989 Phosphorus nutritional requirement of maize seedlings for maximum yield. Agron. J. 81, 95-99.

Clark R B 1983 Plant genotype differences in the uptake, translocation, accumulation, and use of mineral elements required for plant growth. Plant and Soil 72, 175-196.

Da Silva A E and Gabelman W H 1992 Screening maize inbred lines for tolerance to low-P stress condition. Plant and Soil 146, 181-187

Dahnke W C 1988 Recommended chemical soil test procedures for the North Central Region. NCR Publication No. 221. North Dakota State University, Fargo, North Dakota.

Drew MC 1975 Comparison of the effects of of a localized supply of phosphate, nitrate, ammonium, and pottassium on the growth of the seminal root system, and shoot, in barley. New Phytol. 75, 479-490.

Föhse D, Claassen N and Jungk A 1991 Phosphorous efficiency of plants. II. Significance of root radius, root hairs, and cation-anion balance for phosphorous influx in seven plant species. Plant and Soil 132, 261-272.

Fox R H 1978 Selection for phosphorous efficiency in corn Commun. Soil Science Plant Anal. 9, 13-37.

Gelderman R 1990 Soil Testing and Plant Analysis. Plant Science Pamphlet No. 25. South Dakota State University, Brookings, SD.

Grime J P and Hunt R 1975 Relative growth-rate: Its range and adaptive significance in a local flora. J. Ecol. 63, 393-422.

Hanway J J 1966 How a crop plant develops. Spec. Rep. No. 48. Iowa State University. Coop. Ext. Serv. Ames, Iowa $17 \mathrm{p}$.

Hunt R 1982 Plant Growth Curves: The Functional Approach to Plant Growth Analysis. University Park Press, Baltimore. 248 p. 


\section{Phosphorus effects on root development}

Loneragan J F and Asher C J 1967 Response of plants to phosphate concentration in solution culture: II. Rate of phosphate absorption and its relation to growth. Soil Science 103, 311-318.

Nielsen N E and Barber S A 1978 Differences among genotypes of corn in the kinetics of $P$ uptake. Agron. J. 70, 695-698.

Newman E I 1966 A method for estimating the total length of roots in a sample. J. Appl. Ecol. 3, 139-145.

O'Toole J C and Bland W L 1987 Genotypic variation in crop plant root systems. Adv. Agron. 41, 91-145.

Page A L, Miller R H and Keeney D R 1982 Methods of Soil Analysis. Part 2. Chemical and Microbiological Properties. Second Edition. Agronomy 9. 1159p. American Society of Agronomy, Madison, WI.

Robinson D 1989 Phenotypic plasticity in roots and root systems: constraints, compensations and compromises. Asp. Appl. Biol. 22, 49-55.

Schenk M K and Barber S A 1979 Root characteristics of corn genotypes as related to $\mathrm{P}$ uptake. Agron. J. 71, 921-924.

Schumacher T E, Fixen P E and Wicks III Z W 1984 The effect of temperature on the morphology of corn seminal roots. American Society of Agronomy 76th Annual Meeting, Agronomy Abstracts 76, 136.

Wilkinson L 1990 SYSTAT: The System for Statistics. SYSTAT, Inc., Evanston, IL.

Zhang J and Barber S A 1992 Maize root distribution between phosphorus-fertilized and unfertilized soil. Soil Sci. Soc. Am. J 56, 819-822.

Section editor: $H$ Lambers 